những hạn chế nhất định như nghiên cứu chỉ được thực hiện tại một trường cao đẳng, do đó khổng thể suy rộng cho sinh viên hệ điều dưỡng nói chung. Ngoài ra bô câu hỏi được thu thâp bằng phương pháp tự điền do đó sinh viên có thể trao đổi ảnh hưởng đến việc đo lường kiến thức của từng cá nhân.

\section{KẾT LUẬN}

Nói chung, tỷ lệ sinh viên điều dưỡng có kiến thức tốt về COVID-19 khá cao. Tuy nhiên tỷ lệ trả lời đúng thấp đối với các câu hỏi liên quan đến điều trị, các triệu chứng về COVID-19 và hệ thống dự phòng bệnh tại Việt Nam. Bên cạnh đó đa phần sinh viên đã có thái độ tích cực về COVID-19. Do đó, các mảng kiến thức có tỷ lệ trả lời đúng thấp các các yếu tố giới tính cũng như nguồn cung cấp thông tin về Covid-19 cần được xem xét khi thực hiện các khóa đào tạo về sức khỏe cộng đồng cho sinh viên.

\section{TÀI LIẸU THAM KHẢO}

1. Huang $C$, Wang $Y$, Li $X$ et al (2020). Clinical features of patients infected with 2019 novel coronavirus in Wuhan, China. Lancet (London, England), 395(10223), 497-506.
2. Cutler D (2020). How Will COVID-19 Affect the Health Care Economy? Jama, 323(22), 2237-2238.

3. Bô $\mathbf{Y}$ tế. Trang tin về dich bênh viêm đường hô hẩp cấp COVID-19. https:// ncov.moh.gov.vn/ vi/web/guest/ trang-chu. Published 2019. Accessed 24-06-2021.

4. Ha BTT, Ngoc Quang L (2020). Combating the COVID-19 Epidemic: Experiences from Vietnam. 17(9).

5. Ikhlaq A, Hunniya B-E, Riaz IB et al (2020). Awareness and attitude of undergraduate medical students towards 2019-novel corona virus. Pakistan Journal of Medical Sciences, 36(COVID19-S4), S32.

6. Peng $Y$, Pei $C$, Zheng $Y$ et al (2020). Knowledge, attitude and practice associated with COVID-19 among university students: a crosssectional survey in China.

7. Gao Z, Ying S, Liu J et al (2020). A crosssectional study: Comparing the attitude and knowledge of medical and non-medical students toward 2019 novel coronavirus. Journal of infection and public health, 13(10), 1419-1423.

8. Duong MC, Nguyen HT, Duong BT et al The Levels of COVID-19 Related Health Literacy among University Students in Vietnam, Infect Chemother. 2021 Mar;53(1):107-17. doi: 10.3947/ic.2020.0152. Epub 2021 Mar 16.

9. Al-Hanawi MK, Angawi $K$, Alshareef $\mathbf{N}$ et al (2020). Knowledge, Attitude and Practice Toward COVID-19 Among the Public in the Kingdom of Saudi Arabia: A Cross-Sectional Study. Frontiers in public health, 8, 217.

\title{
ĐÁNH GIÁ KẾT QUẢ PHẪU THUÂT NộI SOI MŨI XOANG TYPE III, IV CÓ SỬ DỤNG AQUAMANTYS
}

\section{TÓM TẮT}

Aquamantys là môtt thế hệ dao plasma hàn mach cầm máu mới được ứng dụng trong các phẫu thuật đòi độ chính xác cao và có nhiêu ưu điểm trong câm máu. Mục tiêu nghiên cứu: Đánh giá kết quả sau phẫu thuật nội soi mũi xoang (type III, IV) có sử dụng dao plasma Aquamatys. Phương pháp nghiên cứu: can thiệp có đối chứng gồm 21 bệnh nhân nhóm nghiên cứu (có sử dụng Aquamatys) và 20 bệnh nhân nhóm chứng (không được sử dụng Aquamatys) có chỉ định phẫu thuật nội soi mũi xoang (type III và IV) tại Bệnh viện Đại học Y Hà Nội trong thời gian từ 8/2020 đến 8/2021. Kết quả nghiên cựu: Hệ thống Aquamantys giúp giảm thời gian phẫu thuật, giảm lương máu mất trong phẫu thuât thông qua thời gian phẫu thuật của nhóm nghiên cứu là 78,9 $\pm 22,4$ phút

\footnotetext{
${ }^{1}$ Bệnh viện Đa Khoa tỉnh Quảng Ninh

${ }^{2}$ Trường Đại học Y Hà Nội

Chiu trách nhiệm chính: Vũ Thành Khoa

Email: khoatmhhlqn@gmail.com

Ngày nhận bài: 8.7.2021

Ngày phản biên khoa họ: 3.9.2021

Ngày duyệt bài: 10.9.2021
}

\section{Vũ Thành Khoa ${ }^{1}$, Cao Minh Thành ${ }^{2}$} ngắn hơn có ý nghĩa thống kê so với nhóm chứng là $94,0 \pm 21,5$ phút với $p<0,05$. Và lượng máu mất ở nhóm nghiên cứu là $86,7 \pm 42,3 \mathrm{ml}$ thấp hơn có ý nghĩa thống kê so với nhóm chứng là $116,0 \pm 41,8 \mathrm{ml}$ với $p<0,05$. Triệu chứng cơ năng theo thang VAS cho thây sau phẫu thuật 5 ngày ở nhóm nghiên cứu có xu hướng nhẹ hơn so với nhóm chứng $(p>0,05)$ và sau phẫu thuật 2 tuần và 2 tháng ở nhóm nghiên cứu tương đưởng với nhóm chứng $(p>0,05)$. Triệu chứng thức thể sau phẫu thuât 2 tháng giữa 2 nhóm không thấy khác biệt với $p>0,05$. Bệnh nhân có dính hay xơ seo trong hốc mũi thấp, không khác nhau giữa nhóm nghiên cứu và nhóm chứng. Kết luận: hệ thống Aquạamantys là an toàn và có hiệu quả cẩm máu trong phâuu thuật nội soi mũi xoang.

Tư khóa: nội soi mũi xoang, viêm mũi xoang mạn tính, Plasma Aquamantys, cầm máu

\section{SUMMARY \\ EVALUATION THE RESULT OF ENDOSCOPIC ENDONASAL SURGERY (TYPE III, IV) BY USING AQUAMATYS}

Aquamantys is new generation of coagulate plasma blade applied on precision bleeding control and advantage on coagulate soft tissue. Purpose: 
Evaluation the result of endoscopic endonasal surgery (type III, IV) by using Plasma Aquamatys. Methods: control intervention study of 2 groups (21 patients in study group using Aquamatys and 20 patients in control group no using Aquamatys) had a endoscopic endonasal surgery (type III, IV) in Hanoi Medical University hospital from August 2020 to August 2021. Results: surgery duration reduced in study group (78.9 \pm 22.4 minutes) compared with control group $(94.0 \pm 21.5)$ with $p<0.05$. Average blood loss reduced in study group $(86.7 \pm 42.3 \mathrm{ml})$ compared with control group $(116.0 \pm 41.8 \mathrm{ml})$ with $p<0.05$. Physical symptoms based on VAS was better in study group compared with control group buts $p>0.05$ in day 5 after surgery; and was similar between 2 groups in 2 week and 2 month after surgery. Physical signs was similar between 2 groups in 2 month after surgery with $p>0.05$. There was no different side effects between 2 groups. Conclusion: Aquamantys is safe and effectiveness coagulate in endoscopic endonasal surgery.

Keywords: endoscopic endonasal surgery, endonasal chronic infection, Plasma Aquamantys, coagulation

\section{I. ĐĂT VẤN ĐỀ}

Viêm mũi xoang là môtt trong những bênh hay gặp nhất trong chuyên khoa Tai-Mũi-Họng, bệnh có thể xuất hiện ở cả người lớn và trẻ em, tiến triển kéo dài, ảnh hưởng nhiều đến sức khoẻ và khả năng học tập, lao động. Thống kê trên EPOS 2020 cho thấy $5-12 \%$ dân số toàn cầu bị ảnh hưởng sức khỏe bởi viêm mũi xoang mãn tính. Bệnh không những làm giảm chất lượng cuộc sống mà còn có thể dẫn đến những biến chứng nặng nề, gây nguy hiểm cho tính mạng người bệnh [1]. Điêuu trị nội khoa hoặc ngoại khoa tùy theo tình trạng, tuy nhiên điều trị nội khoa thường kéo dài, do đó bệnh nhân thường không thực hiện đúng chỉ định điều trị. Phẫu thuật được chỉ định phẫu thuật khi điều trị nội khoa thất bại, hoặc giải quyết nguyên nhân, bệnh tích không thể bằng điều trị nội khoa được. Trong đó phẫu thuật nội soi mũi xoang là lựa chon hàng đâu, do mục đích của phẫu thuật là đảm bảo chức năng dẫn lưu, bảo tồn niêm mạc, tuy nhiên theo EPOS 2020 phẫu thuật nội soi chức năng xoang đã được mở rộng như phẫu thuâtt tiệt căn để đảm bảo lấy sạch bệnh tích. Tuy nhiên, đây là phẫu thuật có nguy cơ chảy máu mức độ trung bình, phẫu trường nhỏ nên cần có hệ thống cầm máu tốt để trường phẫu thuật sach qua đó có thể lấy sạch bệnh tích, giảm thời gian phẫu thuật, giảm lượng máu mất và tăng hiệu quả phẫu thuật. Hệ thống cầm máu Plasma Aquamantys đáp ứng được tiêu chí cầm máu tốt, giảm tổn thương mô xung quanh do nhiệt lượng thấp, dễ thao tác, dễ sử dụng, hiện đang được áp dụng trong một số chuyên ngành: thần kinh cột sống, ung bướu, chỉnh hình, nhưng lại chưa sử dụng phổ biến trong phẫu thuật nội soi mũi xoang tại Việt Nam. Vì vậy chúng tôi tiến hành nghiên cứu này với mục tiêu: "Đánh giá kêt quả sau phẫu thuật nội soi mũi xoang type III, IV có sử dụng dao plasma Aquamatys".

\section{II. ĐỐI TƯỢNG VÀ PHƯƠNG PHÁP NGHIÊN CỨU \\ 2.1.Đối tượng nghiên cứu \\ Tiêu chuân lựa chọn}

- Tuổi >16, có chụp phim cắt lớp vi tính mũi xoang tiêu chuẩn tư thế Coronal, Axial và Sagital trước mổ

- Bệnh nhân phẫu thuật nội soi type III, IV

- Bệnh nhân đồng ý nghiên cứu

\section{Tiêu chuấn loai trừ}

- Bệnh nhân phẫu thuật nội soi mũi xoang thuộc các type khác

- Bệnh nhân không đồng ý tham gia nghiên cứu

\subsection{Phương pháp nghiên cứu}

2.2.1. Thiêt kế nghiên cứu: can thiệp có đối chứng gồm 21 bệnh nhân nhóm nghiên cứu (có sử dụng Plasma Aquamantys) và 20 bệnh nhân nhóm chứng (không được sử dụng Plasma Aquamantys) có chỉ định phẫu thuật nội soi mũi xoang (type III và IV) tại Bệnh viện Đại học Y Hà Nội trong thời gian từ 8/2020 đến 8/2021

\subsubsection{Phương tiện nghiên cứu}

- Bệnh án nghiên cứu theo mẫu

- Trang thiết bị khám, phẫu thuật nội soi gồm: bộ nội soi Karl- Storz, camera, dây dẫn sáng và optic $4 \mathrm{~mm} 0$ độ, 30 độ, 70 độ và bộ dụng cụ phẫu thuật nội soi mũi xoang.

- Hệ thống máy IPC của hãng Xomed

Phim chụp cắt lớp vi tính mũi xoang navigation trước phẫu thuật

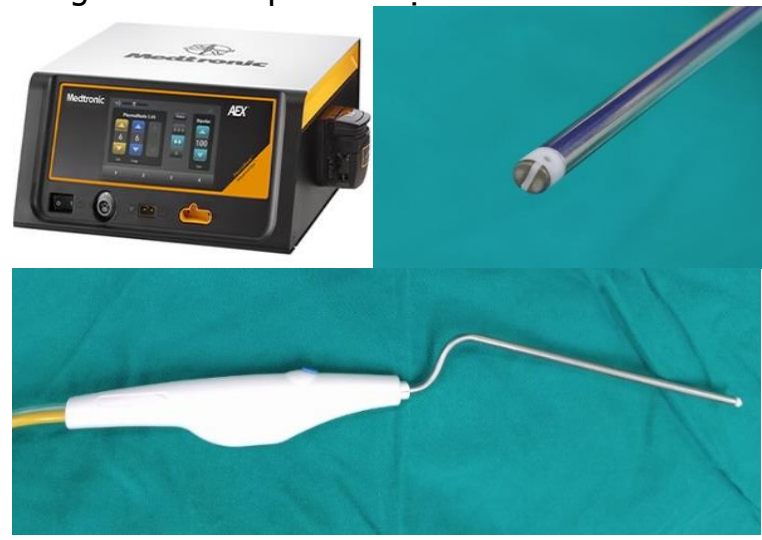

Hình 1. Hệ thống AEX Medtronic, tay Aquamantys

2.2.3. Vật liệu nghiên cứu. Hệ thống $A E X$ Generator với thiết bị hàn mạch Aquamantys 


\subsubsection{Thông sốnghiên cứu}

- Tuổi, giới

- Triệu chứng: cơ năng, thực thể, hình ảnh cắt lớp vi tính.

- Phẫu thuật: lượng máu mất, thời gian phẫu thuật, tai biến

- Sau phẫu thuâat: triệu chứng cơ năng, thực thể

2.3.Xử lý số liệu: Số liệu được phân tích bằng thuật toán thổng kê y sinh học sử dụng phần mềm SPSS 20.0

\section{KẾT QUẢ NGHIÊN CỨU}

\section{1. Đặc điểm chung}

Tuổi, giới: Nhóm nghiên cứu gồm 21 bênh nhân và nhóm chứng gồm 20 bệnh nhân với phân lớp tuổi. Tuổi trung bình của nhóm nghiên cứu và nhóm chứng lần lượt là $45,9 \pm 11,7$ và $46,1 \pm 11,0$ ( $p>0,05)$. Tỷ lệ nam/nữ ở nhóm nghiên cứu là 13 nam/8 nữ và nhóm chứng là $13 / 7$ nũ.

\section{Bảng 1: Lý do vào viện}

\begin{tabular}{|c|c|c|c|c|c|c|}
\hline \multirow[t]{2}{*}{ Lý do vào viện } & \multicolumn{2}{|c|}{$\begin{array}{c}\text { Aquamantys } \\
21 \text { BN }\end{array}$} & \multicolumn{2}{|c|}{$\begin{array}{l}\text { Không Aquamantys } \\
20 \text { BN }\end{array}$} & \multicolumn{2}{|c|}{$\begin{array}{l}\text { Chung } \\
41 \mathrm{BN}\end{array}$} \\
\hline & $\mathbf{n}$ & $\%$ & $\mathbf{n}$ & $\%$ & $\mathbf{n}$ & $\%$ \\
\hline Ngạt mũi & 5 & 23,8 & 5 & 25,0 & 10 & 24,4 \\
\hline Chảy mũi & 1 & 4,8 & 0 & 0,0 & 1 & 2,4 \\
\hline Đau đâu & 3 & 14,3 & 1 & 5,0 & 4 & 9,8 \\
\hline Rối loạn ngứi & 1 & 4,8 & 0 & 0,0 & 1 & 2,4 \\
\hline Ngạt mũi/Chảy mũi & 8 & 38,1 & 7 & 35,0 & 15 & 36,6 \\
\hline Chảy mũi/Đau nhức mắt & 1 & 4,8 & 1 & 5,0 & 2 & 4,9 \\
\hline Chảy mũi/Đau đâu & 2 & 9,5 & 1 & 5,0 & 3 & 7,3 \\
\hline Ngạt mũi/Rối loạn ngửi & 0 & 0,0 & 2 & 10,0 & 2 & 4,9 \\
\hline Đau đầu/Rối loạn ngửi & 0 & 0,0 & 2 & 10,0 & 2 & 4,9 \\
\hline Ngạt mũi/Đau đâu & 0 & 0,0 & 1 & 5,0 & 1 & 2,4 \\
\hline
\end{tabular}

Nhận xét: Các lý do vào viện tương đồng với nhau giữa hai nhóm. Lý do vào viện hay gặp nhất là ngạt mũi, chảy nước mũi.

\section{2. Đặc điêm trước phẫu thuật}

\section{Bảng 2: Phân bố triệu chứng cơ năng}

\begin{tabular}{|c|c|c|c|c|c|c|}
\hline \multirow{2}{*}{ Triệu chứng } & \multicolumn{2}{c|}{ Aquamantys 21 BN } & \multicolumn{2}{c|}{ Không Aquamantys 20 BN } & \multicolumn{2}{c|}{ Chung 41 BN } \\
\cline { 2 - 7 } & $\mathbf{n}$ & $\mathbf{\%}$ & $\mathbf{n}$ & $\mathbf{\%}$ & $\mathbf{n}$ & $\mathbf{\%}$ \\
\hline Ngạt mũi & 19 & 90,5 & 20 & 100,0 & 39 & 95,1 \\
\hline Chảy mũi & 20 & 95,2 & 19 & 95,0 & 39 & 95,1 \\
\hline Đau nhức mũi & 12 & 57,1 & 13 & 65,0 & 25 & 61,0 \\
\hline Đau đâuu & 14 & 66,7 & 17 & 85,0 & 31 & 75,6 \\
\hline Rối loạn ngửi & 8 & 38,1 & 7 & 35,0 & 15 & 36,6 \\
\hline Hắt hơi & 9 & 42,9 & 8 & 40,0 & 17 & 41,5 \\
\hline Ho & 5 & 23,8 & 3 & 15,0 & 8 & 19,5 \\
\hline Khồ họng & 3 & 14,3 & 3 & 15,0 & 6 & 14,6 \\
\hline
\end{tabular}

Nhân xét: Triệu chứng cơ năng giữa hai nhóm là tương tự nhau. Các triệu chứng cơ năng hay gặp nhất là chảy mũi, ngạt mũi, đau nhức mũi, đau đầu, rối loạn ngửi và hắt hới.

Bảng 3: Mức độ viêm các xoang trên CLVT theo thang điểm Lund Mackey

\begin{tabular}{|c|c|c|c|c|c|c|}
\hline \multirow{2}{*}{$\begin{array}{c}\text { Mức độ viêm } \\
\text { các xoang trên } \\
\text { CLVT }\end{array}$} & \multicolumn{2}{|c|}{$\begin{array}{c}\text { Aquamantys } \\
21 \text { BN }\end{array}$} & \multicolumn{2}{|c|}{$\begin{array}{c}\text { Không Aquamantys } \\
20 \mathrm{BN}\end{array}$} & \multicolumn{2}{|c|}{$\begin{array}{l}\text { Chung } \\
41 \text { BN }\end{array}$} \\
\hline & $\mathrm{n}$ & $\%$ & $\mathrm{n}$ & $\%$ & $\mathrm{n}$ & $\%$ \\
\hline Độ 1 & 0 & 0,0 & 0 & 0,0 & 0 & 0,0 \\
\hline Độ 2 & 4 & 19,0 & 3 & 15,0 & 7 & 17,1 \\
\hline Độ 3 & 8 & 38,1 & 10 & 50,0 & 18 & 43,9 \\
\hline Độ 4 & 9 & 42,9 & 7 & 35,0 & 16 & 39,0 \\
\hline Trung bình & \multicolumn{2}{|c|}{$12,9 \pm 3,8$} & \multicolumn{2}{|c|}{$13,6 \pm 3,4$} & \multicolumn{2}{|c|}{$p>0,05$} \\
\hline
\end{tabular}

Nhân xét: Mức độ viêm các xoang trên CLVT tương tự nhau. Sự khác biệt không có ý nghĩa thống kê với $p>0,05$.

\section{3. Đặc điểm trong phẫu thuật}

Bảng 4: Thời gian phấu thuật 
VIETNAM MEDICAL JOURNAL N¹ - OCTOBER - 2021

\begin{tabular}{|c|c|c|c|c|c|}
\hline phầu thuật & $\mathbf{n}$ & $\mathbf{\%}$ & $\mathbf{n}$ & $\mathbf{\%}$ & \\
\hline$<60$ & 3 & 14,3 & 0 & 0,0 & \\
\hline $60-120$ & 15 & 71,4 & 17 & 85,0 & \\
\hline$>120$ & 3 & 14,3 & 3 & 15,0 & \\
\hline Trung bình & \multicolumn{2}{|c|}{$78,9 \pm 22,4$} & \multicolumn{2}{|c|}{$94,0 \pm 21,5$} & $<0,05$ \\
\hline
\end{tabular}

Nhận xét: Thời gian phẫu thuật của nhóm nghiên cứu là 78,9 $\pm 22,4$ ngắn hơn có ý nghĩa thống kê so với nhóm chứng là $94,0 \pm 21,5$ với $p<0,05$.

Trong nhóm nghiên cứu có tới 3 bênh nhân với thời gian phẫu thuật dưới 60 phút chiếm 14,3\%.

Bảng 5: Đánh giá trường phẫu thuật theo thang Boezaart - 1995

\begin{tabular}{|c|c|c|c|c|c|}
\hline Aquamantys & \multicolumn{2}{|c|}{ Có (21 BN) } & \multicolumn{2}{|c|}{ Không (20 BN) } & \multirow[b]{2}{*}{$\mathbf{p}$} \\
\hline Điểm phẫu trường & $\mathbf{n}$ & Số điểm & $\mathbf{n}$ & Số điểm & \\
\hline 1: không chảy máu & 0 & 0 & 0 & 0 & \\
\hline 2: chảy máu ít, không cần phải hút & 5 & 10 & 1 & 2 & \\
\hline $\begin{array}{l}\text { 3: chảy máu nhẹ thỉnh thoảng phải hút, } \\
\text { không đe dọa trường phấu thuật }\end{array}$ & 12 & 36 & 12 & 36 & \\
\hline $\begin{array}{l}\text { 4: chảy máu trung bình, yêu cầu hút liên tục, nếu } \\
\text { ngừng hút máu che lấp hoàn toàn trường phẫu thuật }\end{array}$ & 4 & 16 & 7 & 28 & \\
\hline $\begin{array}{l}\text { 5: chảy máu nă̆ng, hút liên tục vấn không rõ trường } \\
\text { phẩu thuật, không thể thực hiện phẫu thuật. }\end{array}$ & 0 & 0 & 0 & 0 & \\
\hline Trung bình & & 0,52 & 3,3 & $\pm 0,64$ & $<0,05$ \\
\hline
\end{tabular}

Nhận xét: Trong phẫu thuật gặp nhiều nhất là phẫu trường chảy máu nhe, thỉnh thoảng phải hút. ở cả 2 nhóm. So sánh điểm trung bình trường phấu thuật của 2 nhóm có khác biệt với $\mathrm{p}<0,05$

Bảng 6: Mức độ mất máu trong phẫu thuật

\begin{tabular}{|c|c|c|c|c|c|}
\hline \multirow{2}{*}{$\begin{array}{c}\text { Mức độ mất máu } \\
(\mathbf{m l})\end{array}$} & \multicolumn{2}{|c|}{ Aquamantys 21 BN } & \multicolumn{2}{|c|}{ Không Aquamantys 20 BN } & \multirow[b]{2}{*}{$\mathbf{P}$} \\
\hline & $\mathbf{n}$ & $\%$ & $\mathbf{n}$ & $\%$ & \\
\hline$<60 \mathrm{ml}$ & 3 & 14,3 & 1 & 5,0 & \\
\hline $60-120 \mathrm{ml}$ & 13 & 61,9 & 11 & 55 & \\
\hline$>120 \mathrm{ml}$ & 5 & 23,8 & 8 & 40 & \\
\hline Trung bình & \multicolumn{2}{|c|}{$86,7 \pm 42,3$} & \multicolumn{2}{|c|}{$116,0 \pm 41,8$} & $<0,05$ \\
\hline
\end{tabular}

Nhận xét: Lượng máu mất ở nhóm nghiên cứu là $86,7 \pm 42,3 \mathrm{ml}$ thấp hơn có ý nghĩa thống kê so với nhóm chứng là $116,0 \pm 41,8 \mathrm{ml}$ với $\mathrm{p}<0,05$.

3.4. Đánh giá sau phẫu thuật

Bảng 7: Triệu chứng cơ năng theo thang VAS

\begin{tabular}{|c|c|c|c|c|c|c|c|}
\hline \multirow{2}{*}{$\begin{array}{l}\text { Điếm VAS } \\
\text { sau PT } \\
\begin{array}{l}\text { Triệu chứng } \\
\text { cơ năng }\end{array}\end{array}$} & \multicolumn{2}{|c|}{5 ngày } & \multicolumn{2}{|c|}{2 tuân } & \multicolumn{2}{|c|}{2 tháng } & \multirow[b]{2}{*}{$\mathbf{p}$} \\
\hline & 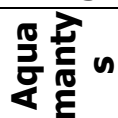 & U & 突至 & 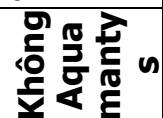 & 突至 & 号 号至 & \\
\hline Ngạt mũi & 6,0 & 6,8 & 4,3 & 4,3 & 3,2 & 3,4 & $>0,05$ \\
\hline Cháy mũi & 6,3 & 7,0 & 4,1 & 4,2 & 2,2 & 2,4 & $>0,05$ \\
\hline Đau nhức mũi & 3,8 & 4,7 & 2,0 & 2,1 & 1,6 & 1,4 & $>0,05$ \\
\hline Đau đầu & 3,6 & 4,3 & 1,9 & 1,8 & 1,2 & 1,5 & $>0,05$ \\
\hline Rối loạn ngửi & 2,2 & 2,1 & 1,8 & 1,7 & 1,6 & 1,6 & $>0,05$ \\
\hline Hắt hơi & $\frac{-12}{1,6}$ & $\frac{2,1}{2,7}$ & 1,4 & 1,5 & 0,9 & $\frac{1,0}{1,1}$ & $>0,05$ \\
\hline $\mathrm{Ho}$ & 0,3 & 0,7 & 0,2 & 0,3 & 0,2 & 0,2 & $>0,05$ \\
\hline Khô họng & 0,5 & 1,4 & 0,4 & 0,6 & 0,3 & 0,2 & $>0,05$ \\
\hline
\end{tabular}

Nhận xét: - Triệu chứng cơ năng sau mố 5 ngày ở nhóm nghiên cứu có xu hướng nhẹ hơn so với nhóm chứng nhưng sự khác biêt không có ý nghĩa thống kê với p > 0,05.

- Triệu chứng cơ năng sau mổ 2 tuần và 2 tháng ở nhóm nghiên cứu tương đương với nhóm chứng $(\mathrm{p}>0,05)$.

Bảng 8: Triệu chứng thực thể sau phẫu thuật 2 tháng theo điểm Lund Kennedy

\begin{tabular}{|c|c|c|c|}
\hline Điểm Lund Kennedy & $\begin{array}{c}\text { Aquamantys } \\
\text { 21 BN }\end{array}$ & $\begin{array}{c}\text { Không Aquamantys } \\
\text { 20 BN }\end{array}$ & p \\
\hline Priệu thực thể & 0,09 & 0,15 & $>0,05$ \\
\hline Phù nề niêm mạc & 1,05 & 1,25 & $>0,05$ \\
\hline
\end{tabular}




\begin{tabular}{|c|c|c|c|}
\hline Tình trạng dịch mũi & 0,76 & 0,85 & $>0,05$ \\
\hline Dính hốc mũi & 0,05 & 0,1 & $>0.05$ \\
\hline Vảy hốc mũi & 0,19 & 0,15 & $>0,05$ \\
\hline
\end{tabular}

Nhận xét: Triệu chứng thực thể sau phẫu thuật 2 tháng giữa 2 nhóm không thấy khác biệt với $p>0,05$.

Bệnh nhân có dính hay xơ sẹo trong hốc mũi thấp, không khác nhau giữa nhóm nghiên cứu và nhóm chứng.

\section{BÀN LUÂNN}

Nghiên cứu chúng tôi được tiến hành với mục tiêu là đánh giá kết quả sau phẫu thuật nội soi mũi xoang type III, IV có sử dụng dao plasma Aquamatys với thiết kế can thiệp có nhóm đối chứng. Vì vậy chúng tôi đã lựa chọn được 21 bênh nhân nhóm nghiên cứu và 20 bênh nhân nhóm chứng có đầy đủ các tiêu chuẩn lựa chọn. Đầu tiên có thể thấy rằng đặc điểm về tuổi trung bình, nhóm tuổi, tỷ lệ giới tính là tương đương giữa hai nhóm với tuổi trung bình của nhóm nghiên cứu và nhóm chứng lần lượt là $45,9 \pm$ 11,7 và $46,1 \pm 11,0(p>0,05)$. Tỷ lệ nam/nữ ở nhóm nghiên cứu là 13 nam/8 nữ và nhóm chứng là 13/7 nữ.

Tiêu chí lựa chọn tiếp theo vào hai nhóm nghiên cứu là các đặc điểm về lâm sàng và cận lâm sàng cũng tương tự nhau giữa hai nhóm nghiên cứu. Theo bảng 1 cho thấy triêuu chứng cơ năng giữa hai nhóm là tương tự nhau. Các triệu chứng cơ năng hay gặp nhất là chảy mũi, ngạt mũi, đau nhức mũi, đau đâu, rối loạn ngứi và hắt hơi. Bảng 2 thì thống kê mức độ viêm các xoang trên cắt lớp vi tính tương tự nhau giữa hai nhóm nghiên cứu với $p>0,05$. Đăcc điểm lâm sàng và cận lâm sàng cũng đồng nhất với các tác giả khác khi mô tả về nhóm bênh nhân này như Phạm Trung Kiên [3], Lê Đức Đông [4], Jae Yong Lee [5].

Để đánh giá về hiệu quả cầm máu trong phẫu thuật, chúng tôi sử dụng tiêu chí về thời gian phấu thuật, lượng máu mất trong phấu thuật và đánh giá trường phẫu thuật. Kết quả cho thây, thời gian phẫu thuật của nhóm nghiên cứu là $78,9 \pm 22,4$ phút ngắn hơn có ý nghĩa thống kê so với nhóm chứng là $94,0 \pm 21,5$ phút với $p<$ 0,05 . Trong nhóm nghiên cứu có tới 3 bệnh nhân với thời gian phẫu thuât dưới 60 phút chiếm 14,3\%. Đánh giá mức độ chảy máu trên trường phẫu thuật theo Boezaart của nhóm nghiên cứu gặp nhiều ở mức 2 và 3 so với nhóm chứng gặp nhiêu ở mức 3 và 4 với $p<0,05$. Lượng máu mất trong phẫu thuật ở nhóm nghiên cứu là $86,7 \pm$
$42,3 \mathrm{ml}$ thấp hơn có ý nghĩa thống kê so với nhóm chứng là $116,0 \pm 41,8 \mathrm{ml}$ với $\mathrm{p}<0,05$. Kết quả này rất phù hợp với các nghiên cứu trước đây khi so sánh giữa hiệu quả của hệ thống Aquamantys so với các dụng cụ cầm máu khác. Trong phẫu thuật thay khớp, điều trị chấn thương khớp cho thấy việc sử dụng hệ thống Aquamantys hiệu quả hơn bipolar ở các chỉ số sau: giảm số lượng máu mất trong phẫu thuật có ý nghĩa thống kê (1067 ml ở nhóm dùng bipolar thường và $662 \mathrm{ml}$ ở nhóm dùng Aquamantys [6]; giảm sự thay đổi nồng độ Hemoglobin trong máu ở nhóm dùng Aquamantys $(3,99 \mathrm{~g} / \mathrm{dl}$ ở nhóm dùng bipolar thông thường và $2,32 \mathrm{~g} / \mathrm{dl}$ ở nhóm dùng Aquamantys) [7]; giảm tỳ lệ phải truyền khối hồng cầu và truyền máu do mất máu (21,2\% bệnh nhân phải truyền máu khi dùng Aquamantys và $23,5 \%$ phải truyền máu ở nhóm dùng bipolar thông thường); giảm số ngày nằm viện của bệnh nhân $(2,9$ ngày nằm viện trung bình với Aquamantys và 3,3 ngày trung bình với nhóm chứng) [8]; nhiều bệnh nhân được ra viện hơn (33,6 \% đối với Aquamantys và 24,1\% đối với nhóm chứng) [8]; giảm tỷ lệ tụ máu sau mổ $(0,2 \%$ tụ máu đối với Aquamantys và $0,8 \%$ đối với nhóm chứng) [8]. Vì đây cũng là kỹ thuật mới áp dụng cho phầu thuật nội soi mũi xoang nên chưa có các nghiên cứu toàn diện mà chì dừng lại chủ yếu ở báo cáo trường hợp lâm sàng.

Kêt quả về triệu chứng cơ năng theo thang VAS cho thấy sau phẫu thuật 5 ngày ở nhóm nghiên cứu có xu hướng nhẹ hơn so với nhóm chứng, nhưng sự khác biệt chưa có ý nghĩa thống kê với $\mathrm{p}>0,05$ và sau mổ 2 tuần và 2 tháng ở nhóm nghiên cứu tương đương với nhóm chứng $(p>0,05)$. Triệu chứng thực thể theo thang Lund Kennedy cho thây sau phẫu thuật 2 tháng ở nhóm nghiên cứu không khác biệt nhóm chứng với $\mathrm{p}>0,05$. Như vậy có thể giả thiết rằng với nhóm nghiên cứu có sử dụng cầm máu bằng Aquamantys giúp bệnh nhân hồi phục nhanh hơn và có thể kết quả điểm cơ năng nhỉnh hơn so với nhóm chứng. Kết quả này cũng tương tự với tác giả Richard Bram [2] khi báo cáo hiệu quả điều trị nội soi mũi xoang bằng Aquamantys cũng khẳng định ưu thế của hệ thống trong cầm máu là giữ cho nhiệt độ không vượt khỏi $100^{\circ} \mathrm{C}$, nên giảm ảnh hưởng của nhiệt độ cao với các mô xung quanh. Tác giả cũng khẳng định hệ thống Aquamantys giúp giảm tỷ lệ 
phải truyền máu cũng như giảm số lượng máu cần truyên. Tác giả đánh giá đây là một phương tiện có khả năng tạo ra xâm lấn tối thiểu, có thể giúp ích cho các phẫu thuật khó như phẩu thuật ở tuyến yên. Trong nghiển cứu này chúng tồi cũng gặp ít bệnh nhân có tai biến xơ dính, đóng vảy trong hốc mũi và tỷ lệ gặp giữa nhóm nghiên cứu và nhóm chứng không có khác biệt. Vì vậy, khi sử dụng hê thống Aquamantys là an toàn và không ảnh hưởng tới tỷ lệ tai biến của phẫu thuật nội soi mũi xoang.

\section{KẾT LUÂNN}

Hệ thống Aquamantys giúp giảm thời gian phẫu thuật, giảm lượng máu mất trong phẫu thuật thông qua thời gian phẫu thuật của nhóm nghiên cứu là $78,9 \pm 22,4$ phút ngẳn hơn có ý nghĩa thống kê so với nhóm chứng là $94,0 \pm$ 21,5 phút với $p<0,05$. Và lượng máu mất ở nhóm nghiên cứu là $86,7 \pm 42,3 \mathrm{ml}$ thấp hơn có ý nghĩa thống kê so với nhóm chứng là $116,0 \pm$ $41,8 \mathrm{ml}$ với $\mathrm{p}<0,05$. Triệu chứng cơ năng theo thang VAS cho thấy sau phẫu thuật 5 ngày ở nhóm nghiên cứu có xu hướng nhẹ hơn so với nhóm chứng $(p>0,05)$ và sau mố 2 tuần và 2 tháng ở nhóm nghiên cứu tương đương với nhóm chứng $(p>0,05)$. Triệu chứng thực thể sau phẫu thuật 2 tháng giữa 2 nhóm không thấy khác biệt với $p>0,05$. Bênh nhân có dính hay xơ seo trong hốc mũi thấp, không khác nhau giữa nhóm nghiên cứu và nhóm chứng. Vì vậy, khi sử dụng hệ thống Aquamantys là an toàn và không ảnh hưởng tới tỷ lệ tai biến của phẫu thuật nội soi mũi xoang.

\section{TÀI LIÊU THAM KHẢO}

1. Fokkens WJ, Lund VJ, Hopkins $C$, et al (2020). European Position Paper on Rhinosinusitis and Nasal Polyps. Rhinology: 58 (Suppl S29):1-464.

2. Bram R, Fiore S, McHugh D, Samara GJ, Davis RP (2017). Hemostasis in endoscopic endonasal skull base surgery using the Aquamantys bipolar sealer: Technical note. J Clin Neurosci. 41:81-85.

3. Phạm Trung Kiên (2019). Nghiên cứu đặc điểm lâm sàng, cắt lớp vi tính, mô bệnh hoc các tổn thương xoang một bên. Luận văn chuyên khoa cấp II, Trường đại học Y Hà Nội.

4. Lế Đức Đông (2019). Nghiên cứu đặc điểm lâm sàng, cận lâm sàng và đánh giá kết quả điều trị phẫu thuật của viêm mũi xoang do nấm. Luận văn chuyên khoa cấp II, Trường đại học Y Hà Nội. tr78.

5. Yong Lee, Jae. (2008). Unilateral paranasal sinus diseases: analysis of the clinical characteristics, diagnosis, pathology, and computed tomography findings. Acta Oto-Laryngologica, 128(6), 621-626.

6. Marulanda G. A., Ulrich S. D., Seyler T. M. et al. (2008), Reductions in blood loss with a bipolar sealer in total hip arthroplasty, Expert review of medical devices, 5(2), 125-131.

7.Clement R. C., Kamath A. F., Derman P. B. et al. (2012), Bipolar sealing in revision total hip arthroplasty for infection: efficacy and cost analysis, The Journal of arthroplasty, 27(7), 1376-1381.

8. Ackerman S. J., Tapia C. I., Baik R. et al. (2014), Use of a bipolar sealer in total hip arthroplasty: medical resource use and costs using a hospital administrative database, Orthopedics, 37(5), e472-e481.

\section{KẾT QUẢ ĐIỀU TRI CHẤN THƯƠNG NGỰC KÈM THEO CHẤN THƯƠ'NG SO NÃO Có DẪN LƯU MÀNG PHỔI ĐƠ'N THUẦN TẠI BỆNH VIỆN HỮU NGHI VIỆT ĐỨC}

\section{TÓM TẮT}

Đắt vấn đề: Chấn thương ngực kèm theo chấn thương sọ não có dẫn lưu màng phổi đơn thuân là một bệnh cảnh lâm sàng năng, chăm sóc và điêu trị thường khó khăn, đòi hỏi tính chuyên khoa hoá cao. Nghiên cứu nhằm tổng kết và đánh giá thực trang về điêu trị và chăm sóc loại hình thương tổn phức tạp này. Phương pháp: Nghiên cứu mô tả cắt ngang; Kết

\footnotetext{
${ }^{1}$ Bệnh viện hữu nghị Việt Đức

Bênh viện đa khoa tỉnh Thanh Hoá

Chịu trách nhiệm chính: Phạm Hữu Lư

Email: phamhuulu@hmu.edu.vn

Ngày nhân bài: 9.7.2021

Ngày phản biện khoa họ: 3.9.2021

Ngày duyệt bài: 10.9.2021
}

Phạm Hữu Lưr1, Dương Văn Minh², quả nghiên cứu ghi nhận ở các biến số: Tuổi, giới tính, lâm sàng, cận lầm sàng, thời gian nằm viện, kết quá điều trị... Số liệu được ghi nhận vào mấu bệnh án nghiên cứu cho từng bệnh nhân và xử lý bằng chương trình SPSS 20.0. Kết quả: Từ tháng 01/2018 đễn 12/2020 có 34 bênh nhân chấn thương ngực có dẫn lưu màng phổi đởn thuần kèm theo chấn thương sọ não được chẩn đoán và điều trị tại Trung tâm Tim mạch và Lồng ngực - Bệnh viện hữu nghị Việt Đức. Thời gian từ khi được dẫn lưu màng phổi đến khi rút dẫn lưu trung bình là 7.3 ngày. Thời gian nằm viện trung bình là 10 ngày. Kết quả tốt chiếm $70.6 \%$. Kết luận: Chẫn thương ngực kèm theo chấn thương sọ não có dẫn lưu màng phổi đơn thuần là mốt trong những là một bệnh cảnh lâm sàng nặng, chăm sóc và điều trị đòi hỏi tính chuyên khoa. Kết quả chăm sóc và điều trị nhóm bệnh nhân nghiên cứu phản ánh thực 